BMJ

Open

Gastroenterology

\section{Maternal inflammatory bowel disease and hypospadias in male offspring: a population-based study in Denmark}

\author{
Ane Birgitte Telén Andersen, Vera Ehrenstein, Rune Erichsen, Trine Frøslev, \\ Henrik Toft Sørensen
}

To cite: Andersen ABT, Ehrenstein V, Erichsen R, et al. Maternal inflammatory bowel disease and hypospadias in male offspring: a population-based study in Denmark. BMJ Open Gastro 2016;3:e000121. doi:10.1136/bmjgast-2016000121

- Additional material is published online only. To view please visit the journal online (http://dx.doi.org/10. 1136/bmjgast-2016-000121).

Received 8 September 2016 Revised 10 October 2016 Accepted 21 October 2016

Department of Clinical Epidemiology, Aarhus University Hospital, Aarhus $\mathrm{N}$, Denmark

\section{Correspondence to} Ane Birgitte Telén Andersen; anebta@gmail.com

\begin{abstract}
Background: The occurrence of inflammatory bowel disease (IBD) and hypospadias has been concurrently increasing, possibly through shared environmental risk factors such as endocrine disrupting compounds. Also, maternal IBD may disturb the normal development of the fetal reproductive tract. However, whether maternal IBD increases the risk of hypospadias in male offspring is unknown. We compared hypospadias risk in sons of mothers with and without IBD.
\end{abstract}

Methods: We used Danish nationwide populationbased registries to conduct a longitudinal prevalence study including all live-born boys from 1979 through 2009. We computed HRs, as estimates of prevalence ratios (PRs), with 95\% Cls for hypospadias, using Cox proportional hazards regression, while adjusting for measured confounding.

Results: Among 966038 live-born boys, 4688 (0.5\%) had a mother with a history of IBD diagnosis before the relevant childbirth. Among the boys with maternal IBD, $36(0.8 \%)$ were diagnosed with hypospadias any time after birth, whereas $6112(0.6 \%)$ sons of mothers without IBD diagnosis had hypospadias (adjusted PR: $1.20,(95 \% \mathrm{Cl} 0.86$ to 1.67$)$. Adjusted PRs for maternal Crohn's disease and ulcerative colitis were $1.38(95 \% \mathrm{Cl} 0.83$ to 2.29$)$ and $1.10(95 \% \mathrm{Cl} 0.71$ to 1.68 ), respectively. Analyses defining hypospadias diagnosis recorded $<6$ months postpartum showed similar results.

Conclusions: We found no convincing evidence of an association between maternal IBD and hypospadias.

\section{INTRODUCTION}

Inflammatory bowel disease (IBD) refers to chronic inflammatory conditions of the intestinal tract including ulcerative colitis (UC) and Crohn's disease (CD). ${ }^{1}$ In most industrialised countries, both the incidence and prevalence of IBD has been increasing over the past decades, with prevalence in Europe reaching $0.5 \%$ for $\mathrm{UC}$ and $0.3 \%$ for $\mathrm{CD}{ }^{2}$ IBD often affects women in their reproductive years. ${ }^{3}$ A study based on the EUROCAT database, a network of population-based

\section{Summary box}

What is already known about this subject?

- The occurrence of inflammatory bowel disease (IBD) and hypospadias, respectively, has been concurrently increasing in most industrialised countries.

- IBD and hypospadias may share environmental risk factors, and furthermore, maternal IBD may disturb the normal development of the fetal reproductive tract.

- The association between maternal IBD and hypospadias in male offspring is poorly examined.

What are the new findings?

- This large population-based prevalence study examined the risk of hypospadias in male offspring of mothers with IBD.

- Among 966038 boys, 4688 (0.5\%) had a mother with an IBD diagnosis before the relevant childbirth. Of 1685 boys with maternal Crohn's disease, 15 were diagnosed with hypospadias $(0.8 \%)$ and of 3003 boys with maternal ulcerative colitis, 21 were diagnosed with hypospadias $(0.7 \%)$. Among the boys without maternal IBD, $6112(0.6 \%)$ had a diagnosis of hypospadias.

- Our study did not provide convincing evidence for an association between maternal IBD and hypospadias in male offspring.

How might it impact on clinical practice in the foreseeable future?

- Our study adds to the knowledge of how IBD affects reproduction and provides reassuring results to patients with IBD.

registries for the epidemiological surveillance of congenital anomalies in Europe, showed that concurrently with IBD, the prevalence of hypospadias has also been increasing. Hypospadias affects $0.3-0.8 \%$ of newborn boys $^{5} 6$ and manifests in an abnormally placed urethral opening on the ventral side of the penis as a result of developmental aberration during gestational weeks $8-14 .^{78}$ 
The concurrent increase in IBD and hypospadias occurrence suggests shared environmental risk factors, for example, endocrine disrupting compounds like phthalates; ${ }^{9} 10$ however, the aetiology of hypospadias remains elusive. ${ }^{7}$ Endocrine disrupting compounds may act as immune modulators and thus be involved in the development of IBD. ${ }^{9}$ They are also associated with androgen downregulation, causing malformations of the male reproductive tract, including hypospadias. ${ }^{11}{ }^{12}$ Furthermore, malnutrition during pregnancy among women with IBD may affect placental-fetal growth and development, ultimately leading to the development of hypospadias. ${ }^{13-15}$ Finally, maternal IBD-related medical treatment and disease activity during pregnancy are associated with intrauterine growth restriction ${ }^{16}$ and may thus also play a role in the development of hypospadias. ${ }^{17}$

Previous studies have examined risks of congenital malformations in children of mothers with $\mathrm{IBD},{ }^{18-22}$ but, to the best of our knowledge, only two studies have reported estimates separately for hypospadias. ${ }^{21} 22$ No association was found in either of the two studies; however, estimates were very imprecise due to a limited number of cases. We conducted a large populationbased prevalence study of the hypospadias risk in male offspring of mothers with IBD, using data from nationwide Danish registries.

\section{MATERIALS AND METHODS}

We conducted this prevalence study using data linked from Danish population-based registries. The Danish National Health Service provides free tax-supported healthcare for the entire Danish population, including free access to general practitioners, hospitals and outpatient clinics, and partial reimbursement of prescribed medications. ${ }^{23}$ We used the civil registration number, a unique personal identifier assigned to each Danish citizen at birth and residents at immigration, to link data from Danish administrative and medical databases. ${ }^{24}$

\section{Study population}

The study included all live-born boys during 1979-2009, identified through the Danish Medical Birth Registry (DMBR). The DMBR has recorded all births in Denmark since 1973 and includes data on both mother and child, such as their civil registration numbers, mother's age at delivery, parity and gestational age. The data are collected by midwives and doctors attending deliveries. $^{25}$

\section{Data on maternal IBD}

Data on maternal IBD were obtained from the Danish National Patient Register (DNPR). The DNPR was established in 1977 and has tracked all discharges from nonpsychiatric hospitals since 1977. Reporting of emergency room and outpatient clinic contacts started in 1995 and diagnoses are coded according to the eighth revision of the International Classification of Diseases (ICD-8) until the end of 1993, and the 10th revision (ICD-10) thereafter. ${ }^{26}$ Besides discharge diagnoses, the DNPR has also tracked surgical procedures. From 1977 to 1995, surgical procedures were coded according to the Danish classification of surgical procedures. Since 1996, they have been coded according to the Nordic Medico-Statistical Committee (NOMESCO) classification of surgical procedures. ${ }^{27}$ We obtained information on maternal IBD diagnoses recorded before each boy's date of birth, defining IBD as a hospital diagnosis of CD or UC. Mothers diagnosed with both $\mathrm{CD}$ and $\mathrm{UC}$ were classified according to the latest diagnosis.

\section{Data on hypospadias}

While severe cases of hypospadias are expected to be diagnosed at birth or shortly thereafter, less severe cases may be diagnosed years postnatally. We therefore defined the outcome as a discharge diagnosis of hypospadias and/or a surgical procedure for correction of hypospadias recorded in the DNPR any time after birth and until 31 December 2010. In Denmark, treatment for hypospadias is centralised and performed by hospitalbased plastic surgeons or urologists in public hospitals. ${ }^{28}$ Since private paediatric inpatient treatment is limited in Denmark, the DNPR comprises virtually complete data on all hospitalisations regarding hypospadias in Denmark.

\section{Data on covariates}

We included information on risk factors for hypospadias using, as appropriate, the DNPR, the DMBR and the Register of Medicinal Product Statistics (RMPS). The RMPS was initiated in 1994 and includes individual-level information on dispensations at all Danish outpatient pharmacies, including dispensation date, name and dose of drug and its Anatomical Therapeutic Chemical (ATC) code. From the DMBR, we included data on year of birth, birth order, mother's age at delivery and smoking during pregnancy (available from 1991 onwards). From the DNPR, we included data on maternal epilepsy, diabetes and preeclampsia diagnosed before or during the relevant childbirth. Finally, from the RMPS, we included data on maternal use of oral contraceptives (at least one dispensation within the past 3 months before the estimated conception date), antidiabetics, antiepileptics and ovulation-inducing drugs. For the latter three drugs, we considered maternal dispensations from 60 days before the estimated conception date until the day of delivery.

All diagnostic, procedure and ATC codes used in this study are provided in the online supplementary appendix.

\section{Statistical analysis}

We computed distributions of children's characteristics at birth according to maternal IBD status. Next, we calculated HRs with 95\% CIs, as estimates of prevalence 
Table 1 Characteristics of boys born in Denmark between 1979-2009 and 1996-2009 according to maternal IBD status, $\mathrm{N}=966038$

\begin{tabular}{|c|c|c|c|}
\hline Characteristics & $\begin{array}{l}\text { Maternal Crohn's disease } \\
(n=1685) \\
n(\%)\end{array}$ & $\begin{array}{l}\text { Maternal ulcerative colitis } \\
(n=3003) \\
n(\%)\end{array}$ & $\begin{array}{l}\text { No Maternal IBD } \\
(\mathrm{n}=961350) \\
\mathrm{n}(\%)\end{array}$ \\
\hline \multicolumn{4}{|l|}{ Number of hypospadias } \\
\hline Overall & $15(0.9)$ & $21(0.7)$ & $6112(0.6)$ \\
\hline $\begin{array}{l}\text { Diagnosed within the first } \\
6 \text { months after birth }\end{array}$ & $9(0.5)$ & $6(0.2)$ & $3512(0.4)$ \\
\hline \multicolumn{4}{|c|}{ Mother's age at delivery (years) } \\
\hline$<25$ & $206(12.2)$ & $290(9.7)$ & $198295(20.6)$ \\
\hline $25-29$ & $618(36.7)$ & 1035 (34.5) & $360712(37.5)$ \\
\hline$\geq 30$ & $861(51.1)$ & $1678(55.9)$ & $402343(41.9)$ \\
\hline \multicolumn{4}{|l|}{ Birth order } \\
\hline 1 & $804(47.7)$ & $1278(42.6)$ & $432383(45.0)$ \\
\hline$\geq 2$ & $881(52.3)$ & $1725(57.4)$ & 528967 (55.0) \\
\hline \multicolumn{4}{|c|}{ Maternal preeclampsia during pregnancy } \\
\hline Yes & 55 (3.3) & $74(2.5)$ & $28364(3.0)$ \\
\hline \multicolumn{4}{|c|}{ Maternal epilepsy during pregnancy } \\
\hline Yes & $17(1.0)$ & $21(0.7)$ & $7691(0.8)$ \\
\hline \multicolumn{4}{|c|}{ Maternal diabetes during pregnancy } \\
\hline \multirow[t]{2}{*}{ Yes } & $13(0.8)$ & $19(0.6)$ & $4750(0.5)$ \\
\hline & $(\mathrm{N}=1311)$ & $(\mathrm{N}=2034)$ & $(\mathrm{N}=454492)$ \\
\hline \multicolumn{4}{|c|}{ Maternal smoking during pregnancy* } \\
\hline No & $931(71.0)$ & 1692 (83.2) & $350728(77.2)$ \\
\hline$\leq 10$ cigarettes/day & $229(17.5)$ & $201(10.1)$ & $65301(14.4)$ \\
\hline$>10$ cigarettes/day & $100(7.6)$ & $55(2.7)$ & $21708(4.8)$ \\
\hline Missing & $51(3.9)$ & $81(4.0)$ & $16755(3.7)$ \\
\hline \multicolumn{4}{|c|}{ Maternal use of oral contraceptives before pregnancy* } \\
\hline Yes & $133(10.1)$ & $202(9.9)$ & $40960(9.0)$ \\
\hline \multicolumn{4}{|c|}{ Maternal use of ovulation-inducing drugs* } \\
\hline Yes & $107(8.2)$ & $183(9.0)$ & $27333(6.0)$ \\
\hline \multicolumn{4}{|c|}{ Maternal use of antidiabetics during pregnancy* } \\
\hline Yes & $9(0.7)$ & $25(1.2)$ & $4148(0.9)$ \\
\hline \multicolumn{4}{|c|}{ Maternal use of antiepileptics during pregnancy* } \\
\hline Yes & $8(0.6)$ & $9(0.4)$ & $2229(0.5)$ \\
\hline
\end{tabular}

ratios (PRs), for the association between maternal IBD with the occurrence of hypospadias in male offspring, using Cox proportional hazards regression, and adjusting for year of birth, birth order, maternal age at delivery, maternal preeclampsia during pregnancy and maternal diabetes and epilepsy before delivery. We examined the PRs of hypospadias by maternal IBD overall and for maternal CD or UC separately. Offspring with no maternal history of IBD were the reference group. To examine if maternal IBD was associated with the severity of hypospadias, we also defined the outcome as a hypospadias diagnosis recorded within the first 6 months after birth. Finally, we repeated the analyses for children born in 1996-2009 which allowed for additional adjustment for maternal use of oral contraceptives, antidiabetics, antiepileptics, ovulation-inducing drugs and maternal smoking during pregnancy.

All analyses were carried out using SAS V.9.2 (SAS Institute, Cary, North Carolina, USA). Studies using data from Danish registries require no approval from an ethical committee or informed consent from patients. The study was approved by the Danish Data Protection Agency (record number 2013-41-1790).

\section{RESULTS}

We identified 966038 boys born in Denmark in 19792009, of whom $4688(0.5 \%)$ had a mother with IBD, with CD accounting for $1685(36 \%)$ of the IBD cases. Sons of mothers with IBD were more likely than those with mothers without IBD to have been born to older women and women using ovulation-inducing drugs. Maternal smoking during pregnancy was more prevalent among sons of mothers with CD than among sons of mothers with UC or without IBD (table 1).

There were $36(0.8 \%)$ boys with hypospadias among boys with maternal IBD. Of the 1685 boys with maternal $\mathrm{CD}, 15$ were diagnosed with hypospadias $(0.8 \%)$ as 
Table 2 Crude and adjusted prevalence ratios for hypospadias in boys in Denmark (1979-2009) according to maternal IBD status, $\mathrm{N}=966038$

\begin{tabular}{|c|c|c|c|c|c|c|}
\hline \multirow[b]{2}{*}{ IBD status } & \multirow[b]{2}{*}{$\begin{array}{l}\text { n } \\
\text { (hypospadias) }\end{array}$} & \multicolumn{2}{|c|}{ Overall hypospadias } & \multirow[b]{2}{*}{$\begin{array}{l}\text { n } \\
\text { (hypospadias) }\end{array}$} & \multicolumn{2}{|c|}{$\begin{array}{l}\text { Hypospadias recorded within } \\
6 \text { months after birth }\end{array}$} \\
\hline & & $\begin{array}{l}\text { Crude PR } \\
(95 \% \mathrm{Cl})\end{array}$ & $\begin{array}{l}\text { Adjusted PR* } \\
(95 \% \mathrm{Cl})\end{array}$ & & $\begin{array}{l}\text { Crude PR } \\
\text { (95\% Cl) }\end{array}$ & $\begin{array}{l}\text { Adjusted PR* } \\
(95 \% \mathrm{Cl})\end{array}$ \\
\hline No maternal IBD & 6112 & 1.00 & 1.00 & 3512 & 1.00 & 1.00 \\
\hline + Maternal IBD & 36 & $1.33(0.96$ to 1.85$)$ & $1.20(0.86$ to 1.67$)$ & 15 & $0.88(0.53$ to 1.45$)$ & $0.81(0.49$ to 1.34$)$ \\
\hline + Maternal CD & 15 & 1.60 (0.96 to 2.65$)$ & 1.38 (0.83 to 2.29$)$ & 9 & 1.47 (0.76 to 2.82$)$ & 1.31 (0.68 to 2.52$)$ \\
\hline + Maternal UC & 21 & $1.19(0.78$ to 1.83$)$ & $1.10(0.71$ to 1.68$)$ & 6 & $0.55(0.25$ to 1.22$)$ & $0.51(0.23$ to 1.14$)$ \\
\hline
\end{tabular}

Table 3 Crude and adjusted prevalence ratios for hypospadias in boys in Denmark (1996-2009) according to maternal IBD status, $\mathrm{N}=457837$

\begin{tabular}{|c|c|c|c|c|c|c|}
\hline \multirow[b]{2}{*}{ IBD status } & \multirow[b]{2}{*}{$\begin{array}{l}\text { n } \\
\text { (hypospadias) }\end{array}$} & \multicolumn{2}{|c|}{ Overall hypospadias } & \multirow[b]{2}{*}{$\begin{array}{l}\text { n } \\
\text { (hypospadias) }\end{array}$} & \multicolumn{2}{|c|}{$\begin{array}{l}\text { Hypospadias recorded within } \\
6 \text { months after birth }\end{array}$} \\
\hline & & $\begin{array}{l}\text { Crude PR } \\
(95 \% \mathrm{Cl})\end{array}$ & $\begin{array}{l}\text { Adjusted PR* } \\
(95 \% \mathrm{Cl})\end{array}$ & & $\begin{array}{l}\text { Crude PR } \\
(95 \% \mathrm{Cl})\end{array}$ & $\begin{array}{l}\text { Adjusted PR* } \\
(95 \% \mathrm{Cl})\end{array}$ \\
\hline No maternal IBD & 2930 & 1.00 & 1.00 & 1881 & 1.00 & 1.00 \\
\hline + Maternal IBD & 31 & 1.47 (1.03 to 2.09$)$ & 1.41 (0.99 to 2.01$)$ & 15 & 1. 09 (0.66 to 1.81$)$ & $1.04(0.63$ to 1.73$)$ \\
\hline + Maternal CD & 14 & $1.69(1.00$ to 2.86$)$ & $1.63(0.96$ to 2.76$)$ & 9 & $1.66(0.86$ to 3.20$)$ & $1.59(0.83$ to 3.07$)$ \\
\hline + Maternal UC & 17 & 1.32 (0.82 to 2.12$)$ & 1.27 (0.79 to 2.04$)$ & 6 & 0.71 (0.32 to 1.59$)$ & 0.69 (0.31 to 1.53$)$ \\
\hline
\end{tabular}

compared with 21 among 3003 boys with maternal UC $(0.7 \%)$. Among the boys without maternal IBD, 6112 $(0.6 \%)$ had a diagnosis of hypospadias. When comparing the boys according to maternal IBD status, the adjusted PR (aPR) for hypospadias was 1.20 (95\% CI 0.86 to 1.67$)$. The corresponding aPRs for $\mathrm{CD}$ and $\mathrm{UC}$ were 1.38 (95\% CI 0.83 to 2.29 ) and 1.10 (95\% CI 0.71 to 1.68 ). In the analysis restricted to boys with hypospadias diagnosed within the first 6 months postnatally, we identified $15(0.4 \%)$ with hypospadias among those with maternal IBD and $3512(0.3 \%)$ among those without maternal IBD. PRs in the restricted analysis were essentially similar to those in the overall analysis (table 2).

In analyses restricted to boys born in 1996-2009 $(\mathrm{N}=457837)$ and with additional adjustment for relevant maternal use of drugs during pregnancy, estimates were slightly elevated compared to those of the main analyses with an aPR of 1.41 (95\% CI 0.99 to 2.01) for maternal IBD. When restricting this analysis to boys with hypospadias diagnosed within the first 6 months postnatally, the aPR was 1.04 (95\% CI 0.63 to 1.73 ) (table 3$)$.

\section{DISCUSSION}

In this large population-based nationwide study, including 966038 boys, we found no convincing evidence for an association between maternal IBD and hypospadias.
Only two previous studies have examined the association between maternal IBD and hypospadias risk in boys. ${ }^{21} 22$ In a population-based case-control study from Hungary based on 3038 boys with hypospadias, 7 of whom were of mothers with UC, the adjusted OR for hypospadias and maternal UC was 1.0 (95\% CI 0.5 to 2.1). ${ }^{22}$ A population-based prevalence study combining Danish and Swedish data included 2377 women with a hospital diagnosis of CD, of whom two gave birth to a son with hypospadias and 869202 women without a diagnosis of CD (number of sons with hypospadias not reported). The authors reported an adjusted OR of 0.52 (95\% CI 0.13 to 2.09) for the association between maternal CD and hypospadias in boys. ${ }^{21}$ Although IBD and hypospadias may share environmental risk factors, ${ }^{9} 10$ our results do not support the existence of a pathway from mother to son.

The strengths of our study include the populationbased design within a universal healthcare system with complete hospital history and no loss to follow-up. Data on maternal IBD and hypospadias were collected independently, reducing the risk of diagnostic bias. Also, our analyses were adjusted for several important risk factors for hypospadias.

There are a number of challenges when examining potential causes of hypospadias through observational research, and therefore our study also has limitations. 
The limited number of hypospadias outcomes did not allow us to examine if hypospadias may be associated with maternal disease activity and/or medical treatment during pregnancy. We adjusted the analyses for several hypospadias risk factors including maternal age at delivery, preeclampsia and, in subanalyses, also maternal use of antiepileptics during pregnancy, but we cannot rule out unknown and unmeasured confounding. Still, a confounder would have to be protective for hypospadias to explain a null result, which we find unlikely. Finally, some misclassification of IBD and hypospadias diagnoses may have occurred. However, the registration of birth defects in the DNPR has acceptable validity for research with a positive predictive value (PPV) of $88 \%$ for congenital abnormalities overall. ${ }^{29}$ Also, a previous Danish study only found three misclassified cases in a record review of 43 boys with hypospadias. ${ }^{30}$ The DNPR also has acceptable validity for IBD diagnosis with PPVs of recorded diagnoses, compared with pathology data and clinical criteria in medical records of $97 \%$ for CD and $90 \%$ for UC. ${ }^{31}$ Any potential misclassification is likely to be non-differential and could have biased the results towards the null.

In conclusion, adding to the existing evidence, this nationwide study did not provide convincing evidence that maternal IBD increases the risk of hypospadias.

Contributors ABTA took part in study concept and design, data analysis plan, interpretation of data, manuscript writing, manuscript revision, editing and decision to publish. VE, RE and HTS were involved in study concept and design, data analysis plan, interpretation of data, revision of manuscript, editing and decision to publish. TF took part in study concept and design, data analysis, interpretation of data, revision of manuscript, editing and decision to publish. All authors had full access to all data.

Funding The study was supported by Colitis-Crohn Foreningen in Denmark, the Clinical Epidemiology Research Foundation, Aarhus University Hospital,

Denmark, and by the Program for Clinical Research Infrastructure (PROCRIN) established by the Lundbeck Foundation and the Novo Nordisk Foundation and administered by the Danish Regions. The Department of Clinical Epidemiology, Aarhus University Hospital, receives funding for other studies from companies in the form of research grants to (and administered by) Aarhus University. None of these studies have any relation to the present study.

Competing interests None declared.

Provenance and peer review Not commissioned; externally peer reviewed.

Data sharing statement No additional data are available.

Open Access This is an Open Access article distributed in accordance with the Creative Commons Attribution Non Commercial (CC BY-NC 4.0) license, which permits others to distribute, remix, adapt, build upon this work noncommercially, and license their derivative works on different terms, provided the original work is properly cited and the use is non-commercial. See: http:// creativecommons.org/licenses/by-nc/4.0/

\section{REFERENCES}

1. Getahun D, Fassett MJ, Longstreth GF, et al. Association between maternal inflammatory bowel disease and adverse perinatal outcomes. J Perinatol 2014;34:435-40.

2. Molodecky NA, Soon IS, Rabi DM, et al. Increasing incidence and prevalence of the inflammatory bowel diseases with time, based on systematic review. Gastroenterology 2012;142:46-54.e42; quiz e30.

3. Schulze $\mathrm{H}$, Esters $\mathrm{P}$, Dignass $\mathrm{A}$. Review article: the management of Crohn's disease and ulcerative colitis during pregnancy and lactation. Aliment Pharmacol Ther 2014;40:991-1008.
4. Loane M, Dolk H, Kelly A, et al. Paper 4: EUROCAT statistical monitoring: identification and investigation of ten year trends of congenital anomalies in Europe. Birth Defects Res A Clin Mol Teratol 2011;91(Suppl 1):S31-43.

5. Lund L, Engebjerg MC, Pedersen L, et al. Prevalence of hypospadias in Danish boys: a longitudinal study, 1977-2005. Eur Urol 2009;55:1022-6.

6. Shih EM, Graham JM, Jr. Review of genetic and environmental factors leading to hypospadias. Eur J Med Genet 2014;57:453-63.

7. Kraft KH, Shukla AR, Canning DA. Hypospadias. Urol Clin North Am 2010;37:167-81.

8. Manson JM, Carr MC. Molecular epidemiology of hypospadias: review of genetic and environmental risk factors. Birth Defects Res Part A Clin Mol Teratol 2003;67:825-36.

9. Kuo $\mathrm{CH}$, Yang SN, Kuo PL, et al. Immunomodulatory effects of environmental endocrine disrupting chemicals. Kaohsiung J Med Sci 2012;28(7 Suppl):S37-42.

10. Kalfa N, Philibert P, Baskin LS, et al. Hypospadias: interactions between environment and genetics. Mol Cell Endocrinol 2011;335:89-95.

11. Lottrup $\mathrm{G}$, Andersson AM, Leffers $\mathrm{H}$, et al. Possible impact of phthalates on infant reproductive health. Int J Androl 2006;29:17280; discussion 181-5.

12. Ormond G, Nieuwenhuijsen MJ, Nelson P, et al. Endocrine disruptors in the workplace, hair spray, folate supplementation, and risk of hypospadias: case-control study. Environ Health Perspect 2009;117:303-7.

13. Chen MJ, Macias CG, Gunn SK, et al. Intrauterine growth restriction and hypospadias: is there a connection? Int $J$ Pediatr Endocrinol 2014;2014:20

14. Hussain N, Chaghtai A, Herndon CD, et al. Hypospadias and early gestation growth restriction in infants. Pediatrics 2002;109:473-8.

15. Rhind SM. Effects of maternal nutrition on fetal and neonatal reproductive development and function. Anim Reprod Sci 2004;8283:169-81.

16. Broms G, Granath F, Linder M, et al. Birth outcomes in women with inflammatory bowel disease: effects of disease activity and drug exposure. Inflamm Bowel Dis 2014;20:1091-8.

17. Hashimoto $\mathrm{Y}$, Kawai M, Nagai S, et al. Fetal growth restriction but not preterm birth is a risk factor for severe hypospadias. Pediatr Int 2016;58:573-7.

18. Ban L, Tata LJ, Fiaschi L, et al. Limited risks of major congenital anomalies in children of mothers with IBD and effects of medications. Gastroenterology 2014;146:76-84.

19. Dominitz JA, Young JC, Boyko EJ. Outcomes of infants born to mothers with inflammatory bowel disease: a population-based cohort study. Am J Gastroenterol 2002;97:641-8.

20. Stephansson O, Larsson H, Pedersen L, et al. Congenita abnormalities and other birth outcomes in children born to women with ulcerative colitis in Denmark and Sweden. Inflamm Bowel Dis 2011;17:795-801

21. Stephansson O, Larsson H, Pedersen L, et al. Crohn's disease is a risk factor for preterm birth. Clin Gastroenterol Hepatol 2010;8:509-15.

22. Norgard B, Puho E, Pedersen L, et al. Risk of congenital abnormalities in children born to women with ulcerative colitis: a population-based, case-control study. Am J Gastroenterol. 2003:98:2006-10.

23. Schmidt M, Pedersen L, Sorensen HT. The Danish Civil Registration System as a tool in epidemiology. Eur J Epidemiol 2014;29:541-9.

24. Pedersen CB. The Danish civil registration system. Scand J Public Health 2011;39(7 Suppl):22-5.

25. Blenstrup LT, Knudsen LB. Danish registers on aspects of reproduction. Scand J Public Health 2011;39(7 Suppl):79-82.

26. Lynge E, Sandegaard JL, Rebolj M. The Danish National Patient Register. Scand J Public Health 2011;39(7 Suppl):30-3.

27. Smedby B, Schiøler G. Health classifications in the Nordic countries Historic development in a national and international perspective 2006. Copenhagen: NOMESCO, 2006.

28. Erichsen R, Mikkelsen E, Pedersen L, et al. Maternal use of proton pump inhibitors during early pregnancy and the prevalence of hypospadias in male offspring. Am J Ther 2014;21:254-9.

29. Larsen $\mathrm{H}$, Nielsen GL, Bendsen J, et al. Predictive value and completeness of the registration of congenital abnormalities in three Danish population-based registries. Scand J Public Health 2003;31:12-16.

30. Pedersen L, Norgaard M, Rothman KJ, et al. Loratadine during pregnancy and hypospadias. Epidemiology 2008;19:359-60.

31. Fonager K, Sorensen HT, Rasmussen SN, et al. Assessment of the diagnoses of Crohn's disease and ulcerative colitis in a Danish hospital information system. Scand J Gastroenterol 1996;31:154-9. 